Historic, Archive Document

Do not assume content reflects current scientific knowledge, policies, or practices. 


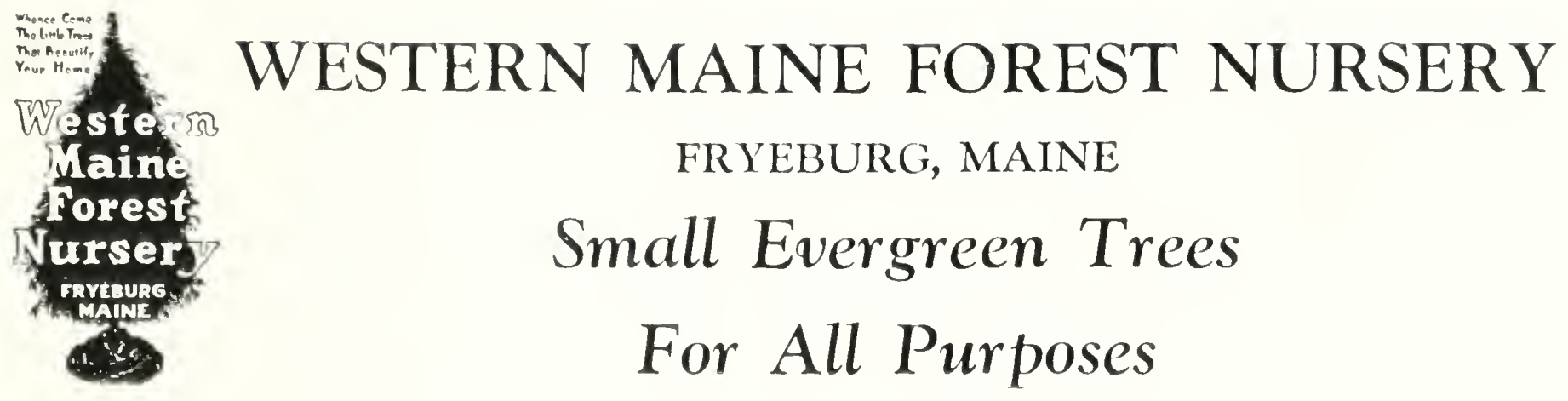

Fryeburg, Maine.

To Evergreen Lovers:

If you want a real thrill take a peek at the inclosed list of evergreens! We wish you could walk around our nurseries and see these little trees, each variety with a different type of appeal, and all of them sturdier than ever for having lived and thrived through unusually dry weather. YOU WOULD BE SO ENTHUSIASTIC YOU WOULD WONDER IF THERE WERE ANY VARIETY YOU COULD DO WITHOUT. Some you would want for their sheer beauty of line and color, some for their grace; others for their picturesqueness, and others, like people, for their very dependability.

Of course values are greater than ever this year--you expect that--but do notice the increase of twice-transplanted stock and the new varieties available. And SOMETHING SPECIAL: to each $\$ 10$ worth of trees ordered and paid for before September 10, we will add 10 beautiful Norway and White Spruce that will be from eight inches to a foot high!

Be sure to see the information about "Fall Planting" on page 3. Set your trees out this fall if you possibly can, and send in your order at once in order to get the "Something Special."

Yours faithfully,

WESTERN MAINE FOREST NURSERY. 


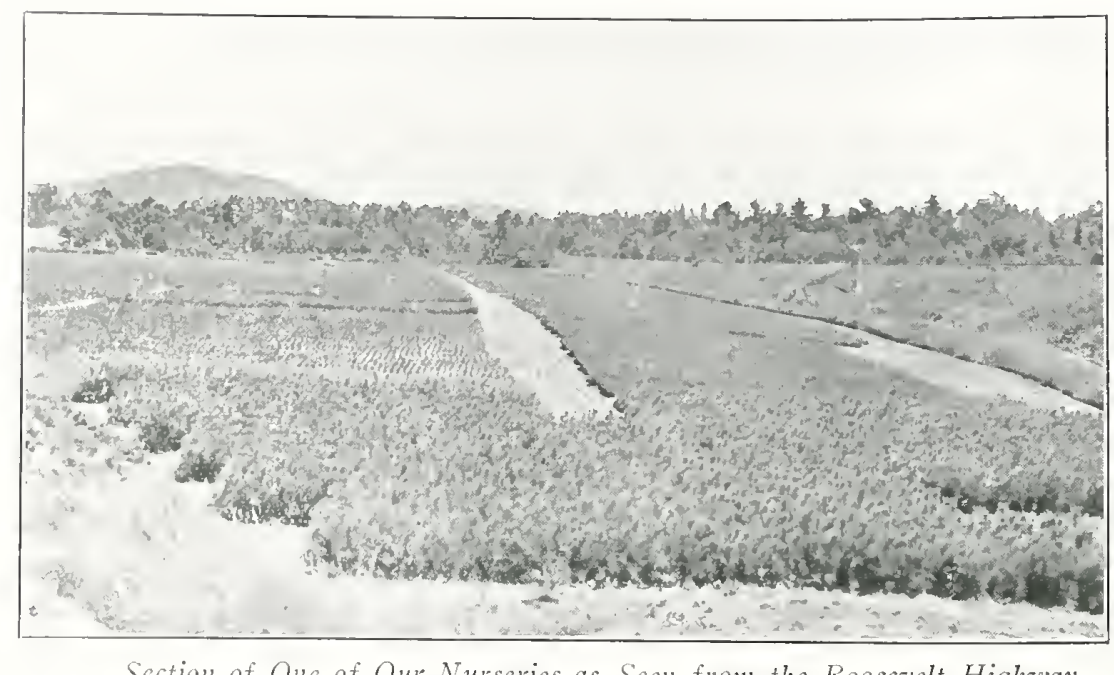

\section{Description and Soil Requirements of Varieties Offered}

WHITE SIRUCE Upright and symmetrical; light, silvery green foliage. Makes satisfaetory hedges and windbreaks. Will stand elipping and pruning. I'refers heavy soil and will grow in shade. Average 60-75 feet at maturity.

NORWAY SIRLCE Graceful, symmetrical tree of rapid growth. Pendulous branehes, dark green foliage. Makes goorl herlges and windloreaks, as well as speeimen trees. Will grow in shade and will live in either light or heary soil. Average about 80 feet at maturity.

COLORADO The handsome ungrafted, short-leaved tree native of Colorado.

BLLE SPRUCE Ranging in shade from slightly blue-green to marvelous blue. Grows in any soil; prefers sunlight. Average at maturity, 80 feet.

ENGLEMANN last growing spruee with a soft blue-green foliage. Often a more beatiful shade of blue than the

SPRUCE Colorado Blue Spruee. Average at maturity, 80 feet.

BALSAM FIR Symmetrieal, fragrant. Flat blue-green needles. Prefers medium to heavy soil and will grow in shade. Average about 50 feet at maturity.

IVIITE PINE The most beatiful native evergreen of New England. Has long lustrous needles; light green with silvery glint. Thrives in any soil, shade or sunlight. Average at maturity, 90 feet.

MUGHO PINE Dwarf, slow-growing. Hardy everywhere exeept in wet soils.

DOUGLAS FIR Soft dark green to gray-blue needles. Rapid grower, about $r_{0}$ feet at maturity.

HEMLOCK Lacy graceful foliage, easily pruned. If unpruned at maturity, 70 feet. Likes shade, will live in sunlight.

RED PINE Dense foliage, beautiful, long, deep green needles. Rapid growing. Will thrive in dry soil. Requires sunlight. Average at maturity, 100 feet.

SCOTCH PINE Rapid growing and very ornamental. Light gray-green foliage. Will grow in poor soil and adverse eonditions. Good for screens where quick growth is required. Average at maturity, 50-60 feet.

AUSTRIAN PINE Vigorous grower; long dark green foliage. Will thrive in sandy dry soil. Excellent for seashore plantings. Average 50-60 feet at maturity.

RED CEDAR A juniper, formal in habit, rieh in eolor, somewhat eolumnar in growth. Prefers sun, but lives in moderate shade. Likes all but heavy wet soil. Exeellent foundation species.

\section{FALL PLANTING}

Fall planting is successful on a type of soil that does not heave with the aetion of the frost in the spring and especially so if the trees are planted far enough in advanee of the winter season so that the roots ean get some anchorage before the winter starts. Sometimes the fall season is dry; if so, it is little or no trouble to oceasionally water a snall number of trees and we recommend this practice after planting trees during a dry fall.

In order that trees may get settled hefore the winter, we suggest that they be planted as soon after September first as is practical in your climate. If you are in doulst, place your order at onee, and we will send the trees to you at the proper time.

Care of Trees UNP.ACK TREES PROMPTLY WHEN RECEIVED. If not planted immediately: Heel them in.

Upon Arrizal (Place roots in shaded place, if possible, in furrow and paek dirt firmly over them. Keep moist. Do not crowd.) Roots Must Never Be Allowed to Dry Out. T'ory Important.

How to Plant These trees can he planted with a trowel or light shovel. Make a hole 8 or 9 inehes deep and 6 inches in diameter. Aiter filling the hole half full of water, insert the tree in an upright position and pack the dirt firmly around it. Water the trees regularly for the first week or two after planting, and oceasionally thereafter, especially if the weather is dry. 


\title{
FALL PRICE LIST
}

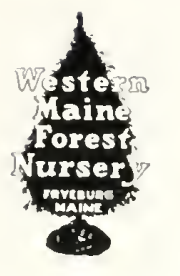

COLLECTION No. 4

$\$ 3.50$
COLLECTION No. 7

$\$ 7.00$

\author{
(See Page 1i) \\ "T" indicates once transplinterl \\ "T"T" inclicates twice transplanted
}

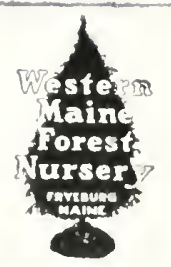

American Arborvitae
American Arborvitae
American Arborvitae
Austrian Pine
Balsan Fir
Balsam Fir
Canadian Hemlock
Clinese Elni
Colorado Plue Spruce
Colorado Blue Spruce
Concolor Fir
Douglas Fir
Douglas Fir
Englemann Spruce
European Larch
Japanese Larch
Japanese Larch
Mlugho Pine
Norway Spruce
Norway Spruce
Norway Spruce
Oriental Pyramidal Arborvitae
Red Cedar
Red Cedar
Red (Norway) Pine
Red (Norway) Pine
Red Norway) Pine
Scotch Pine
White Pine
White Spruce
White Spruce

1 yr. T

i) ir. T

ii ir. TT

1 yr. T

t ir. T

;y. TT

(; yr. T'

+ ir. TT

4 y. $T$

i) yr. TT

ij yr. T'T

1 yr. T

$5 \mathrm{yr}$. T'T

s yr. T'T

+ yr. T

i) $\mathrm{yr}, \mathrm{T}$

i yr. T

t vr, T

$+\mathrm{yr} . \mathrm{T}$

5 yr. TT

$6 \mathrm{yr} \cdot \mathrm{T} T$

3 yr. T

$3 \mathrm{yr}, \mathrm{T}$

6 $\mathrm{yr}$. TT

$4 \mathrm{yr} \cdot \mathrm{T}$

5 yr. TT

6 yr. 'T'T

3 yr, T

4 yr. T

4 yr. T

$5 \mathrm{yr}, \mathrm{TT}$

\begin{tabular}{|c|c|c|c|}
\hline Inclies & Per 100 & l'er:i & ber 10 \\
\hline $1-8$ & $\$ 2.00$ & $\$: .00$ & $\$ 1.111$ \\
\hline$(i-12$ & 10.001 & $\because . . ;$ & 1.50 \\
\hline $12-15$ & 15.000 & 1.00 & $\because: 3$ \\
\hline $8-17$ & 10.00 & ?...is & 1.50 \\
\hline$i-8$ & $\therefore .00$ & 2.00 & 1.00 \\
\hline$(i-10$ & $10.00)$ & 2.65 & 1.50 \\
\hline$(j-10)$ & $\because 0.110$ & $\therefore . i n 11$ & 3.00 \\
\hline $1:-15$ & 20.00 & 5.50 & 3.00 \\
\hline $1-6$ & 8.00 & 2.50 & 1.50 \\
\hline $6-10$ & 12.00 & 3.50 & 2.00 \\
\hline $3-6$ & $\because .00$ & $\because .00$ & 1.00 \\
\hline$\therefore-10$ & 10.00 & $2 . i \mathrm{i}$ & 1.50 \\
\hline $8-12$ & 15.00 & 4.00 & 2.25 \\
\hline $6-10$ & 15.00 & +.00 & 2.25 \\
\hline $8-15$ & 7.00 & $\because .00$ & 1.00 \\
\hline $8-1:$ & 3.50 & 1.00 & $\therefore 0$ \\
\hline $1:-18$ & 7.00 & $\therefore .00$ & 1.00 \\
\hline$t-5$ & 7.00 & 2.00 & 1.00 \\
\hline $5-10$ & 3.50 & 1.00 & .50 \\
\hline $8-12$ & 7.00 & 3.00 & 1.00 \\
\hline $12-15$ & 10.00 & 2.85 & 1.50 \\
\hline $2-6$ & 3.50 & 1.00 & .50 \\
\hline $2-4$ & 3.50 & 1.00 & .50 \\
\hline $9-12$ & 20.00 & 5.50 & 3.00 \\
\hline $5-10$ & 3.50 & 1.00 & .50 \\
\hline $8-15$ & 7.00 & 2.00 & 1.00 \\
\hline $12-24$ & 20.00 & 5.50 & 3.00 \\
\hline $3-6$ & 3.50 & 1.00 & .50 \\
\hline $5-10$ & 3.50 & 1.00 & .50 \\
\hline $5-10$ & 3.50 & 1.00 & .50 \\
\hline $8-12$ & 7.00 & 2.00 & 1.00 \\
\hline
\end{tabular}

* White Pine may be shipped only in New England.

Fifty trees of the same kind and size at the one hundred rate. No order accepted at the above prices for less than ten trees of any one variety and size.

Shipping Weight: Trees averaging less than 10 inches - 10 11ss. per 100 trees.

(Approximate) Trees averaging $8.1 \%$ inches-15llss, per 100 trees.

Trees averaging $10-1$ is inches - 18 lbs. per 100 trees.

Transportation: These little trees will be carefully tagged, wrapped in waterproof paper and burlap, and we guarantee their delivery to you in gond condition when shipped by express. All shipments go collect and your express agent or postmaster will give you the rate to your address. You will be surjorised how little it will be. Gn orders of less than 50 trees of the $4-8$ inch size (or equivalent) going short distances parcel post is sometimes cheaper than express. In this case add 15 cents to your order to cover insurance charges, as the Post office department is not responsible for parcel post unless insured. For all other shipments we reconment express.

Claims: If stock does not arrive in goorl condition, advise at once. A card will he mailes when your order is sent; allow ample time for their arrival, then write us if not received; do not wait several weeks.

Terms: Net cash. If C.O.D. shipment is desired, 50 per cent of the amount must accompany the order as a guaranty. 
To Transplant After the trees have been planted two or three years, if you want to move them, cut around each tree with a shovel and lift out with a good ball of earth. Plant as above. (Transplanting increases the density of the foliage and improves the shape of the tree.)

General Care All the trees listed are large enough so that they may be planted safely in their permanent places, but better results may be obtained if they are set out in a corner of your garden or other cleared area where they can be watered during especially dry seasons until they become large enough to make a showing wherever they may be used. In this case they should be set about one foot apart and they may be left for three or four years, if so desired, without heing moved. If you wish to prevent rapid growth, nip off the terminal buds in the early spring.

Root Pruning Root pruning is not necessary when trees are in their permanent places. It is helpful, however, in making a tree dense. Since a tree's root system is about equal to its crown (foliage) to root prune, cut around the tree with a sharp sparle at about the same distance from the base as the branches are from the trunk. Root pruning is advisable when trees are to be moved at some future date.

Fertilizer We recommend the use of Vigoro on all your trees, plants, shrubs and lawns. We can furnish this batanced ration for plants in $5-1 \mathrm{~b}$, packages for $60 \mathrm{c}$ or in $25-\mathrm{lb}$. bags for $\$ 2.00$.

II ater All of the trees offered have taken care of themselves for two years, but in hot climates or where the soil is dry, judicious watering would be beneficial.

Mulching In climates where there is considerable frost during the winter with little snow for protction, illuiching contributes to the acclimatization of evergreens, although hundreds of our friends have grown our trees without any mulching whatever. Peat, moss, old leaves or hay are effective mulchers.

Shading Shading is rarely necessary, but in extremely hot, dry climates it does no harm and might in some instances be of benefit.

\section{USES FOR EVERGREENS:}

HEDGES For this purpose we recommend the use of one species rather than an assortment. For slow growing hedges use arborvitae or hemlock: spruce for the medium hedge; and pine, especially Red and Scotch pine, for the high hedge or windbreak. Trees should be planted two feet apart and later every other one can be taken out, if you wish.

FOUNDATION If fast growing trees are used near foundations, prevent too rapid growth by yearly root pruning and nipping off terminal buds as soon as trees reach a height of a few feet.

WINTER

Spruce or Fir can be arranged very attractively in small window boxes for the outside of your

WINDOW BOXES home. They will live in the boxes throughout the winter and in the spring may be planted on your lawn or in your garden.

LIVING POTTED Spruce or Fir may be planted in small pots and used for inside decorations during the

CHRISTMAS TREES Christmas season. In this case they need to be watered daily and should not be subjected to extremely high temperatures. If they are not kept too long indoors they can be planted in window boxes or in your garden after the holidays and continue to live.

ADAPTATION Our trees have been successfully sent to all parts of the United States and to several foreign counTO VARIOUS tries, where they adapted themselves very well. Soil conditions apparently have as much to do with CLIMATES the adaptability of most species as the geographic locations. (See soil requirements.)

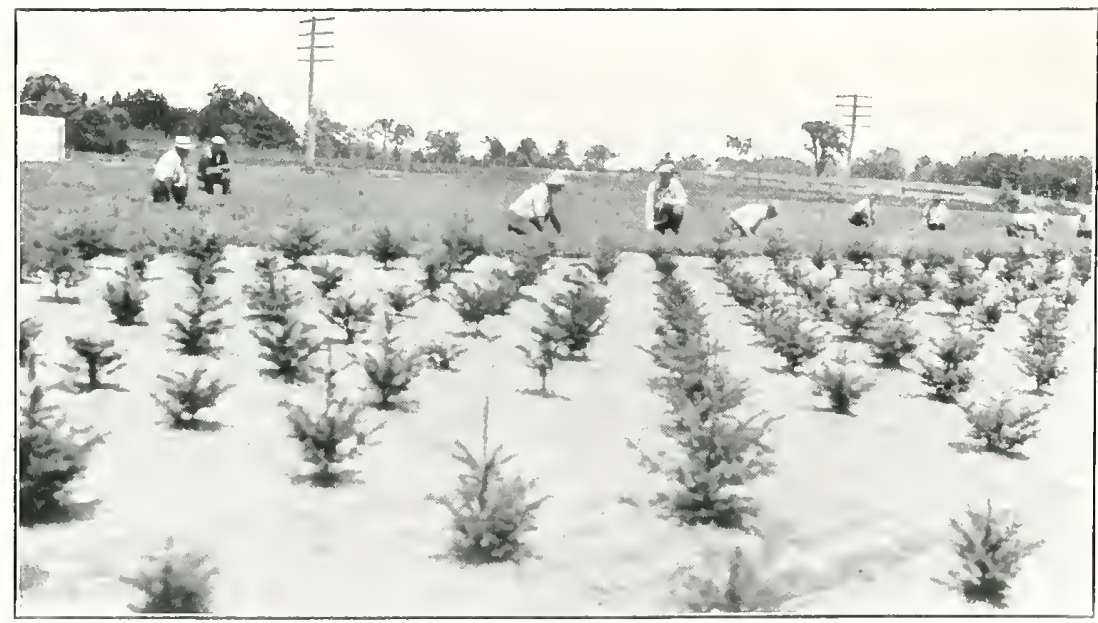

Men IIreding Four-I'car-Old Trecs al Nurscry No. 2 


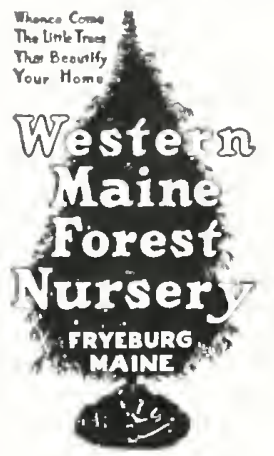

\section{Portions of Unsolicited Letters}

\section{from Our Customers}

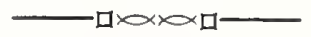

"The hundred small plants that you sold me last fall have all lived and the pines have grown from seven to twelve inches, and the spruces about six inches each." (New York)

"I just want to tell you how satisfied I was with the little trees you sent me. They were lovely and considering what I paid for them the ones I got from you are more satisfactory in every way than the ones I have bought of other concerns." (New Jersey)

"The spruce arrived in fine shape and are set out. I am nearly eighty years of age, have receivert a gond many plants liut never saw better." (New York)

"Regarding the 50 Colorado Blue and 25 Englemann Spruce sent me last fall-I am pleased to report a 'Perfect Stand' and the same was practically true of the Red, White, and Austrian Pine, Norway and White Spruce, and American Arborvitae. Wonderful, sturdy little conifers at the right price." (Connecticut)

"The hundred trees received from you last year are doing fine." (California)

"I want to thank you for the way in which you handled my order. Out of the 75 trees sent me every single one is living and doing fine." (Indiana)

"I wish to thank you for the prompt service you have rendered me with every order, also the quality and size of the trees was very satisfactory. I hope to have more orders in the near future." (Ohio)

"Your shipment of the 14 th arrived today and can say I am more than pleased with the fine trees, the size, the sturdiness, and the root development. It was more than I expected. I have bought trees of the same kind this spring from one of the foremost nurseries in Illinois, but can say that I am sorry I had not hearr of your firm before and ordered all my trees from you." (Illinois)

"Last spring I received a small trial order of 100 evergreen trees from you. I was much pleased with the stock I receiverl. I did not lose a one and it was a very dry season here." (Pennsylvania)

"The shipment of trees ordered from you came yesterday, were in fine shape. You certainly understand packing trees for distance shipping. These were seemingly as fresh as if they had just been dug. I was very much pleased with the trees. They were larger than I had expected and so well rooted." (Arkansas) 


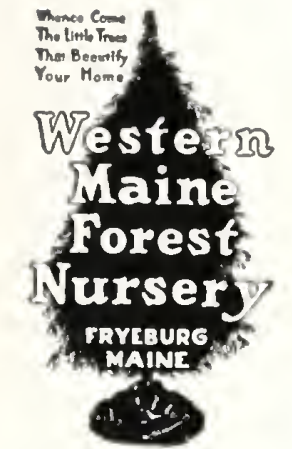

Postmaster: If unable to deliver

please return. Postage guaranteed.
Sec. $435 \frac{1}{2}$, P. L. \& R.

U. S. POSIAGE

Paid

PERMIT NO. 1

FRYEBURG, MAINE

Horticultur al Crops \& Iiseases

$\checkmark$. S. Lept. of tagicul ture

Vashington, D. C.

\section{DON'T MISS THESE TWO SPECIAL OFFERS}

\section{COLLECTION No. 7}

Consisting of 8 heautiful everereen trees reaty for use around your home. Nll at least s years old, $1:$ to lo inches tall and several times transplanterl. Shipped with a ball of earth on the roots.

Special Price-\$. $\$ 00$ for \& trees. any assortment, or $\$ 1.00$ for one tree.

Balsam lin

Hemlock

White sipruce

Norway Spruce

Pramidal Srhorvitae

Austrian Pine

kerl I'ine

Green Colorato sinuce
COLLECTION No. 4

100 t-yeat transplants. is to 10 inches tall. 25 each of the following watietics. all for \$si.ion.

:.) Ninway spruce $\because$ K Ked ( Norway) Pine

.; White spruce

$\because$ Trees, nut choice, either

Imerican Arborvitae, Iutrian F'ine, European Larch Shipping weight: about $10 \mathrm{lbs}$.

Shipping weight: about so 11 s.

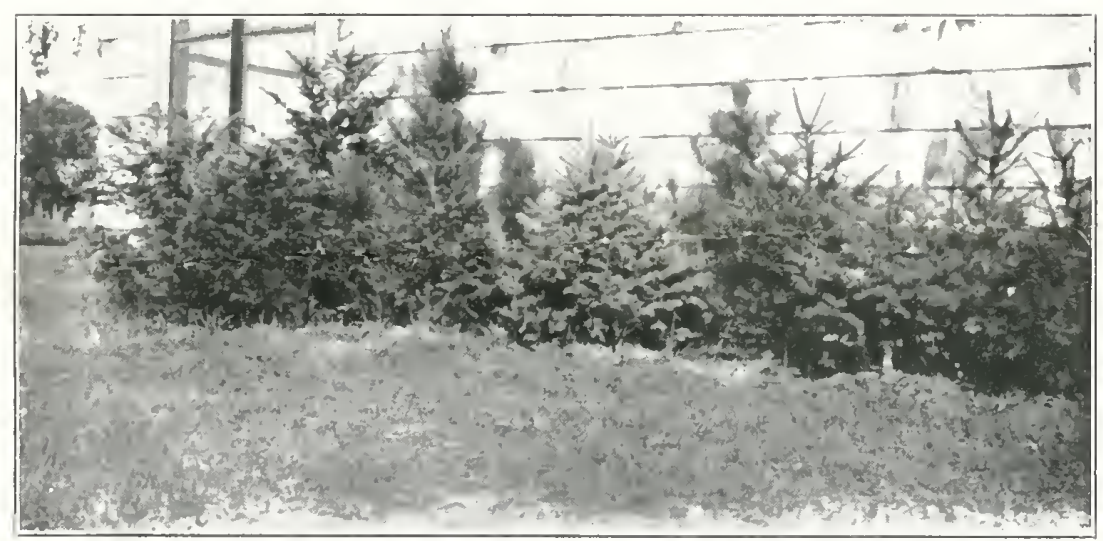

A Hew of Our Small Trees Three I'cars After P'lanting 
